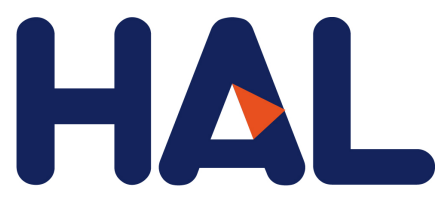

archives-ouvertes

\title{
Computational Alternatives Vignettes for Place- and Activity-Centered Digital Services in Public Libraries
}

\author{
Aurélien Tabard
}

\section{To cite this version:}

Aurélien Tabard. Computational Alternatives Vignettes for Place- and Activity-Centered Digital Services in Public Libraries. Proceedings of the 2020 CHI Conference on Human Factors in Computing Systems, 2020, 10.1145/3313831.3376597 . hal-03178569

\section{HAL Id: hal-03178569 \\ https://hal.archives-ouvertes.fr/hal-03178569}

Submitted on 23 Mar 2021

HAL is a multi-disciplinary open access archive for the deposit and dissemination of scientific research documents, whether they are published or not. The documents may come from teaching and research institutions in France or abroad, or from public or private research centers.
L'archive ouverte pluridisciplinaire HAL, est destinée au dépôt et à la diffusion de documents scientifiques de niveau recherche, publiés ou non, émanant des établissements d'enseignement et de recherche français ou étrangers, des laboratoires publics ou privés. 


\section{Computational Alternatives Vignettes for Place- and Activity-Centered Digital Services in Public Libraries}

\author{
Daisy Yoo \\ Aarhus University, Denmark \\ dyoo@cc.au.dk
}

\author{
Aurélien Tabard \\ Alix Ducros \\ LIRIS, CNRS UMR5205, \\ Université Lyon 1, France \\ aurelien.tabard@liris.cnrs.fr \\ alix.ducros@liris.cnrs.fr
}

\author{
Peter Dalsgaard \\ Clemens Nylandsted \\ Klokmose \\ Aarhus University, Denmark \\ dalsgaard@cavi.au.dk \\ clemens@cavi.au.dk
}

\author{
Eva Eriksson \\ Aarhus University, Denmark \\ Chalmers University of \\ Technology, Sweden \\ evae@cc.au.dk
}

\author{
Sofia Serholt \\ University of Gothenburg, \\ Chalmers University of \\ Technology, Sweden \\ sofia.serholt@ait.gu.se
}

\begin{abstract}
We investigate how to design community technologies for public events. We do so with a focus on technologies that give rise to new forms of participation and knowledge coproduction in public libraries. Specifically, we deployed a digital service at a major public library during its four-week creative workshop series. The system offered an alternative way for people to work together as a community, to go beyond achieving individual goals, and to contribute to the achievement of public goals (e.g., building community bookshelves). We report on how the system has reconfigured physical spaces and afforded new social practices in the library. We propose Computational Alternatives as a fruitful approach for gaining situated, nuanced insights into a technology's possible adoption. We offer key insights in the form of computational alternatives vignettes - grounded stories that encapsulate sociotechnical implications of technology, pointing to plausible alternative futures.
\end{abstract}

\section{Author Keywords}

Computational Alternatives; public libraries; library events; place-centric; knowledge sharing; third places.

\section{CCS Concepts}

-Human-centered computing $\rightarrow$ Human computer interaction (HCI); User studies;

\section{INTRODUCTION}

Libraries are no longer places of silence. Increasingly, public libraries organize a variety of events, ranging from public readings to exhibitions to hands-on participatory activities such as creative workshops and makerspaces. Events at public libraries are inherently open to broad audiences and are complementary to the libraries' rich collections. Not only do these library events offer opportunities for teaching and learning, they can also provide space for local residents to meet up, converse, and collaborate with each other. In essence, library events hold high potential for strengthening the social fabric of local communities. At the same time, library events pose new challenges for the library staff, who struggle to balance their new role of an event organizer with their traditional librarianship [31]. While much time and effort are put into organizing an event, most events go undocumented and unarchived; knowledge and resources generated in the events are lost. Although commercial platforms such as Facebook, Instagram, or wikis are used to share information about library events, it is done on a case-by-case basis, creating a tension between digital content controlled by external actors and public libraries' mission for democratizing knowledge.

With this research, we explore ways to support public libraries in organizing events and making the events more accessible for the wider community. We seek to understand how to best support public participation in documenting and curating library events: How can we design a system that enables library users and library staff to co-produce knowledge and resources and make the outcomes visible for the benefit of the wider community?

We present the design of PLACED, a place- and activitycentered library service. PLACED is comprised of two parts: a documentation module for sharing user-generated content via mobile devices, and a visualization module for public displays in the library. This system differs from existing social media in that it is semi-anonymous, partly curated, and 
mostly local. PLACED offers an alternative way for people to work together as a community, to go beyond achieving individual goals (e.g., training skills, entertainment) by contributing to the achievement of public goals (e.g., creating a local archive, building a community bookshelf). Technically, it builds on Webstrates [22], a malleable software stack that enables rapid prototyping and deployment of new features. Methodologically, we draw from Computational Alternatives [23], an emerging methodology within Participatory Design [32] that emphasizes the importance of deploying high-fidelity prototypes in a real-world setting to study local, situated social practices around technology.

We report a case study of the deployment of PLACED in the context of a creative workshop series in a major public library in Aarhus, Denmark. We describe the system's use, how it reconfigured physical spaces, and afforded new social practices in the library. Based on our empirical findings, we offer a set of design insights for implementing place- and activity centered digital services in public libraries. Particularly, we present them in the form of computational alternatives vignettes - grounded stories that encapsulate sociotechnical implications of technology.

The key contribution of this paper is two-fold: (1) we provide domain-specific insights on how technology may support community co-production of knowledge in public libraries; and (2) we demonstrate how a Computational Alternatives case study conducted in a very particular, situated context can support envisaging sociotechnical futures in a highly nuanced manner, ergo the plausible alternative futures [30].

\section{RELATED WORK}

\section{Computational Alternatives}

Computational Alternatives [23] is a part of a growing body of work in human computer interaction (HCI) that engages with sociotechnical implications of design. The focus on complex sociotechnical issues calls for studying the situatedness of design [20], recognizing its emergent and dynamic nature beyond initially configured user needs, technical requirements, and environmental settings. This co-evolution among stakeholders, technology, and environment is difficult to study, and even more so, to anticipate. A number of methods have been developed to study the sociotechnical dimension of design in situ, ranging from Cultural Probes [15] to Technology Probes [21] and to Research Products [25]. Together these methods point to "a shift in discourse around understanding technologies in situ - not only for the short trajectory of a research project but for the extended engagement over the long term. This shift in discourse has presented new ways of thinking and reporting on designing for prolonged use and larger scale deployments" [33]. Computational Alternatives extend these prior efforts by its theoretical grounding in Participatory Design (PD), development of concrete technical systems, deep situatedness, and projections of plausible alternative futures.

Computational Alternatives were originally conceived as an argument against a lost ambition of building technology in the "increasingly less-technical PD community" [23]. Korsgaard et al. [23] lamented that PD has become so focused on "feel good processes" of participation rather than development of concrete technical systems [38]. They proposed Computational Alternatives to reinvigorate a technical research interest into PD by using high-fidelity prototypes as the focal point for design collaboration among the participants. Prototypes materialize technological principles and visions in a way that makes them tangible to stakeholders and that allows social interactions to unfold. Such prototypes should be of high enough fidelity with multiple layers of core functionality in order to create a convincing user experience. Prototypes should be robust enough to be deployed for a sustained period of time so that researchers can study their long-term sociotechnical implications. To that end, Computational Alternatives differ from more conceptual and exploratory approaches such as Technology Probes.

Technology Probes act as an object of inquiry, to challenge preexisting ideas and influence future design. Technology Probes are not thought of as a fully-featured product, nor intended for long term use. Instead, Technology Probes value simplicity, focusing on a single main function to test; a deliberate lack of certain functionality might be chosen to provoke user reactions. While the critical and future oriented aspects of Technology Probes are particularly relevant to us, through our prior experience working with Technology Probes on various Participatory Design projects [35, 34], we have found that their rudimentary and provoking aspects could get in the way of generating deep stakeholder engagement. The temporary and simplistic nature of Technology Probes can be detrimental to understanding the complex interplay among stakeholders, technology, and their environment. To address the shortcoming, we turned to Computational Alternatives.

Computational Alternatives represent a methodology in line with Bertelsen et al.'s call for research for the very particular [3], where the aim is not to design universal or generic solutions "but rather focuses on addressing the particular challenges of particular people in particular situations or activities" [3, p. 35]. High fidelity prototypes are designed to fit into a very particular context, to be embedded in the existing technological infrastructure and social constraints, which set up the stage for people's day-to-day interactions. Through deep situatedness, Computational Alternatives can establish what Engeström calls a microcosm [13].

Computational Alternatives offer a promising middle ground between (a) studies of adoption and appropriation, anchored in existing technological infrastructures and in a given socioeconomic context [7], and (b) speculative design [12], which can be detached from, or at least does not concretely have to respond to, technical, social, or economic constraints. By deploying alternative technologies exploring different (not necessarily "innovative" or "provocative") technological paths in a specific context, Computational Alternatives bring the opportunity to envision plausible snippets of future use, and outline paths for adoption. 


\section{Designing for Public Libraries and Communities}

We explore Computational Alternatives in the context of public libraries. Libraries occupy a special role in communities, as they are some of the few third places that are not subsumed under commercial interests [28]. However, libraries' traditional role as knowledge hubs has been challenged by pervasive access to digital media. In response, many libraries are working to redefine their role and public perception, moving beyond the traditional role of being a repository for books, to play a more active role as a place for community building and knowledge exchange across social and cultural divides [2, 29, 17]. This includes an increased focus on organizing and hosting events such as public debates, author visits, book clubs, makerspaces, and much more.

Yet, there has been little focus on developing digital services to support libraries in the above-mentioned transition; instead, most digital services have focused on digitizing content and providing access to library collections. This means that if the library staff and library users wish to use digital services to organize events or share the knowledge generated in those events, they have to rely on external services that are typically (a) not designed for this purpose, (b) driven by commercial interests that may clash with those of the library, and (c) not otherwise connected to library services and infrastructures, meaning that the content created is not subsequently visible or accessible via library services $[1,37]$. Inspired by previous research projects that have examined Participatory Design in libraries $[10,8,39]$ and other forms of public knowledge institutions [9], we employ a Computational Alternatives approach to examining how a new type of digital services may support library staff and library users in organizing events, capturing and sharing the knowledge acquired during these events, and building and strengthening local communities that arise around these events.

\section{PLACED PROJECT}

\section{Prior Work}

The frame for the study presented in this paper is a European research project with eight partners from Denmark, France, and Sweden, including research universities and public libraries in each country. Our work draws and expands upon research on designing for third places, particularly in the context of public libraries. Our research labs have collaborated with public libraries and citizens to design of digital services for libraries for the past 15 years.

The development of PLACED builds on extensive prior work, including a series of field observations and co-design workshops as well as an early prototype, which we have tested in the wild on a one-off basis. Specifically, we carried out ethnographic studies in libraries in three countries, each with a duration of approximately two weeks. This was supplemented with focus group sessions with library staff, to understand their mindsets, visions, values, and concerns surrounding library practices and technology adoption. In addition, we conducted co-design workshops [5] focusing on planning and orchestration of events in the libraries. We then developed an initial prototype, which was intentionally very generic, as a means for demonstrating and critically discussing the potentials and implications of novel services with library staff and library users.

\section{Design Process}

Building on all this prior work, we turned to develop a new prototype, with which we aimed at building a high-fidelity, functioning system that could be deployed in the field for an extended period of time. We focused on one particular series of events in one particular library in order to offer in-depth descriptions and analysis of the system's use.

Compared to traditional user-centered approaches, our "users" are highly varied, and include among others library patrons with a particular interest in the collections, those who come to the libraries for the events but who may have little interest in the collection, newcomers and frequent attendees, multiple generations of patrons, and very different levels of digital literacy. Moreover, when designing novel services we have had to consider the needs of external event organizers as well as the library staff, and more broadly the library's mission of providing and mediating access to knowledge. Given the broad audience we design for, rather than focusing on a well-defined group of users, we opted for a "research for the very particular" approach [3], in which we, in collaboration with local libraries, hand-picked a selection of particular events to design for. We thus developed a custom-made version of the service for each specific event type in situ, with the intent of creating grounded insights into the sociotechnical implications of introducing these services, and of envisioning concrete design opportunities. The approach thus echoes Bertelsen: "Taking a very particular approach can enable us to capture the richer and more complex nuances of a particular situation or user, hence also directly challenging the assumptions we make as researchers" [3]. From the knowledge we gain from one particular case, we can proceed with another particular case as the next step to expand upon. [27].

We selected the Creative Workshop series at the main public library of Aarhus, Denmark for our case study based on two important criteria: (1) Frequency: We sought an event that happened frequently enough on a regular basis. The Creative Workshop sessions occur twice a week all year long. Such frequency granted us time to develop the necessary trusting relationship with the event organizer to be able to engage in a Participatory Design process for the system development, go through multiple design iterations, and deploy PLACED for a sustained period of time. (2) Relevance: The goal of the Creative Workshop series is to introduce participants to different creative practices so that people can learn new skills, get inspired, and connect with each other through making. The Creative Workshop series is participatory and generative in nature, which resonated with our project goal.

A new prototype was developed in close collaboration with the Creative Workshop organizer over the period of nine months (Oct 2018 - Jun 2019) with additional feedback from our partner libraries in France and Sweden via focus groups and informal interviews. As part of this process, we developed a detailed service blueprint [40], which informed the design of a novel system. 


\section{UI and Implementation}

PLACED aims at supporting the documentation and visualization of content generated during library events. PLACED consists of two modules: a documentation module designed for mobile devices, and a visualization module for interactive public displays in the library.

The documentation module is a web application to be used on smartphones, with which event organizers (i.e., library staff) and participants can document their ongoing events via three key features: (1) "Share Ideas" (photos, videos, polls, Q\&A) which captures and shares local knowledge; (2) "Share Books" which links the library event with its book collection; and (3) "Share Inspirations" for more open-ended use (see Figure 1). Library staff can moderate posts or decide to share specific content on the visualisation module.

The visualization module offers a list of past and upcoming events, and for each event, it displays the content that was generated using the documentation module (as shown in Figure 2). Users can interact with the content through touch, e.g., zoom for images and playback for video files.
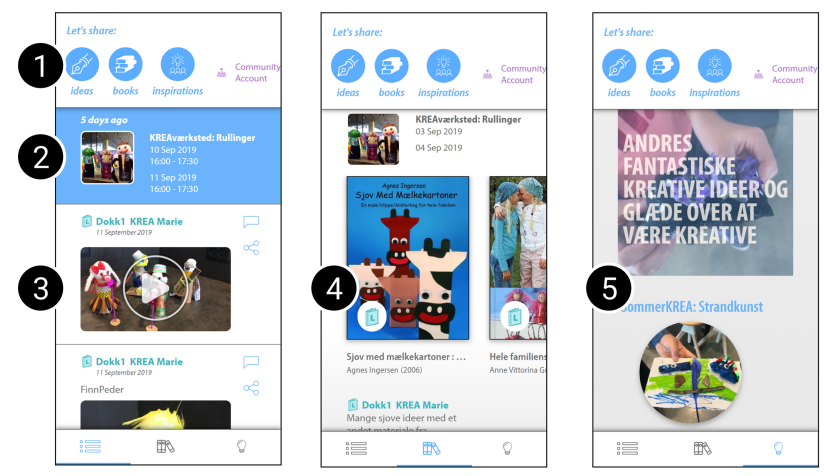

Figure 1. The documentation module offers three key features for sharing: "Ideas" (left), "Books" (center) and "Inspirations" (right). (1) At the top are the buttons for adding content, followed by (2) the the event info. The rest of the screen is then dedicated to (3) the posts, (4) book recommendations or (5) inspirational items.

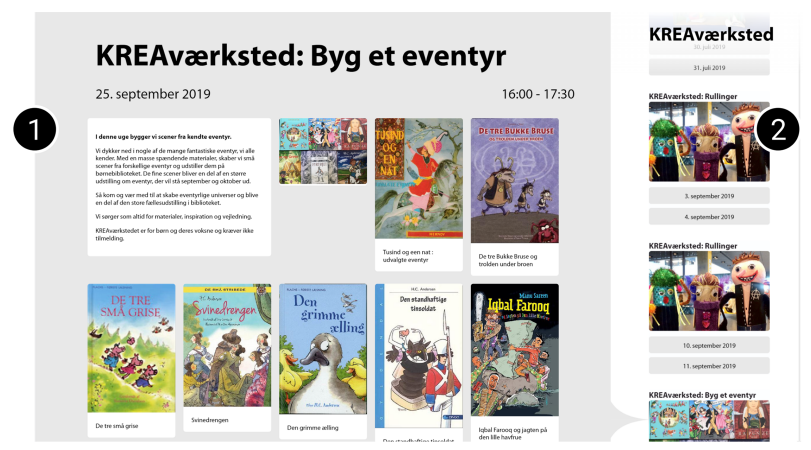

Figure 2. The visualization module retrieves content from the documentation module. (1) On the left is the mosaic of content, (2) on the right is the list of events.

The documentation module is built on Webstrates [22]. Webstrates is a web-platform with built-in support for collaboration and real-time sharing of content between users.
The visualization module is a VueJS ${ }^{1}$ website, which distributes and displays the content based on a polling mechanism. Photos and videos posted via the documentation module are displayed approximately 1 to 2 minutes later on the public display.

Both modules are connected to the library calendar and collection APIs to gather information about the events, and integrates books from the collections (see Figure 3).

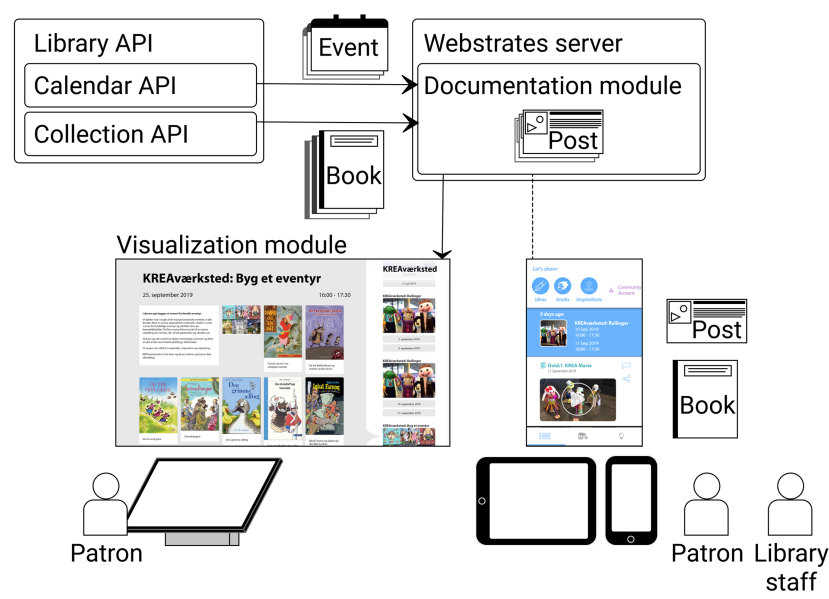

Figure 3. Architecture of the platform

\section{Deployment}

PLACED was deployed for four weeks during the summer holiday season from July 2 to 31, 2019. The Creative Workshop was open every Tuesday and Wednesday from noon to 3 p.m. Participants were free to drop-in at any time during the session; registration was not needed. The Creative Workshops series is a family-friendly event open for all ages. Typically, participants attended in small groups of young children accompanied by adults. The workshop theme changed from week to week, and included Music Instruments, Hair Accessories, Mobiles, and Beach Art. Throughout a 3-hour session, $62-119$ library visitors participated in the workshop, depending on the popularity of the theme $(\mathrm{M}=85$; av ratio of children to adults $=14: 9$ ).

The size of the workshop area is about $50 \mathrm{~m}^{2}$. The room can accommodate approximately 22 participants at a time (see Figure 5). The visualization module was set up outside the workshop area, approximately 4.8 meters from the entrance (see Figure 4). Still, participants could see the visualization module from within the workshop area through the glass wall. We used a 55-inch interactive public display for the visualization module. The center of the screen was about 110 centimeters high from the floor, making it low enough for children to reach and interact with. Next to the visualization module, there was a non-interactive public display streaming short animations without sound. In front, there was a couch facing towards the screens (see Figure 6).

\footnotetext{
${ }^{1}$ https://vuejs.org
} 


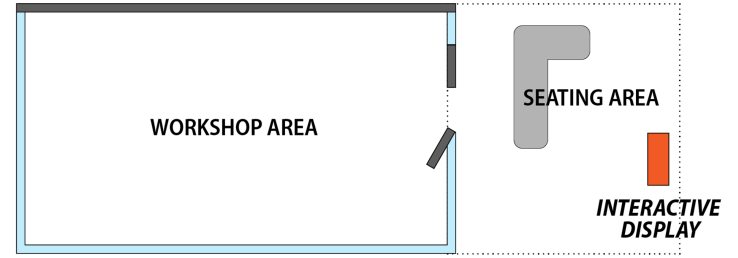

Figure 4. Layout of the research site.

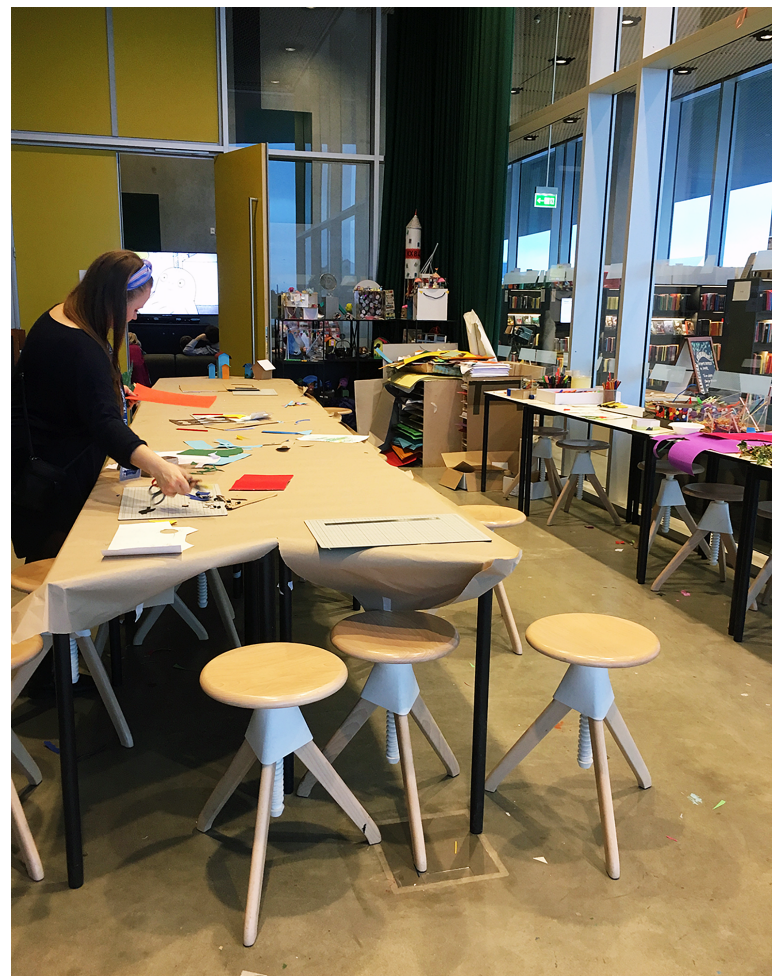

Figure 5. View from within the workshop area. The workshop organizer is cleaning up the workshop table after the event.

Prior to the field trial, the first author conducted multiple ethnographic observations of the Creative Workshop sessions, as well as a contextual inquiry with the event organizer, to gain a deep understanding of the existing practice settings. On week 1 and week 2, two researchers (including the first author) were on the site to observe. The researchers were standing by the visualization module to answer questions and assist the users as appropriate. On week 3, we intentionally removed ourselves from the site so that people could use and experiment with the PLACED on their own; hence, the researchers were not present on the site. On week 4, one researcher was back on the site to observe. This time, the researcher observed from a distance using the fly-on-the-wall technique [18]. In other words, the researcher was made unknown to the users; only the event organizer was aware of the presence of a researcher on the site.

\section{Data collection and analysis}

We kept field notes and took photos to document our observations, but did not make any audio or video recordings of the activities. Field notes were taken and analyzed using the

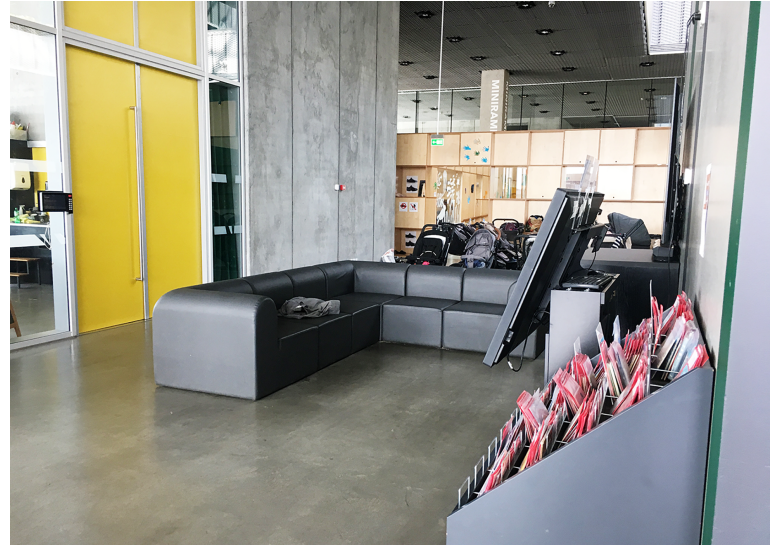

Figure 6. Physical setting of the visualization module.

situated evaluation method [6], specifically, centering on the following questions: (a) how our system has been used (or gone unused) by different users across different devices, (b) how it has reconfigured physical spaces and (c) how it has afforded new social practices in the library.

In addition, we collected and analyzed the user generated content. We included researcher-generated contents in the analysis if the content was generated on behalf of the users upon explicit request (e.g., "Can you upload this picture for me?", "Can you please make a video for us?"). Otherwise, we removed researcher-generated content from the data set.

When referring to the stakeholders we use the following terms:

Event organizer refers to the Creative Workshop organizer who is also a part-time library staff.

Event participants refer to those who participated in the Creative Workshop.

Users refer to all of those who interacted with PLACED including library visitors and the library staff who did not necessarily take part in the Creative Workshop series.

Quotes in italics were translated to English from Danish.

\section{SUMMARY OF USE}

We looked at the content created by the users in order to understand the type of knowledge they documented and shared using PLACED. We collected 243 valid posts created through the system over the four-week period (see Table 1 for details), and organized our findings into three categories according to the primary features of our system: Ideas, Books, and Inspirations. In the following subsections, we present key findings with illustrative examples from the logged data.

\section{Ideas}

The number of posts on the Ideas feature increased over time from 16 posts during week 1 to 70 posts during week 4 . Although the Ideas feature allowed users to generate four distinct types of posts (photos, videos, polls, and Q\&A), users generated only photos and videos (158 photos and 31 videos; 189 total). Neither polls nor Q\&A were created. 


\begin{tabular}{cccccc}
\hline Week & Theme & Photos & Videos & Books & Insp. \\
\hline 1 & Music Instruments & 6 & 10 & 0 & 1 \\
2 & Hair Accessories & 54 & 0 & 20 & 1 \\
3 & Mobiles & 27 & 21 & 21 & 0 \\
4 & Beach Art & 71 & 0 & 11 & 0 \\
\hline & Total & 158 & 31 & 52 & 2 \\
\hline
\end{tabular}

Table 1. Content generated during the four-week deployment.

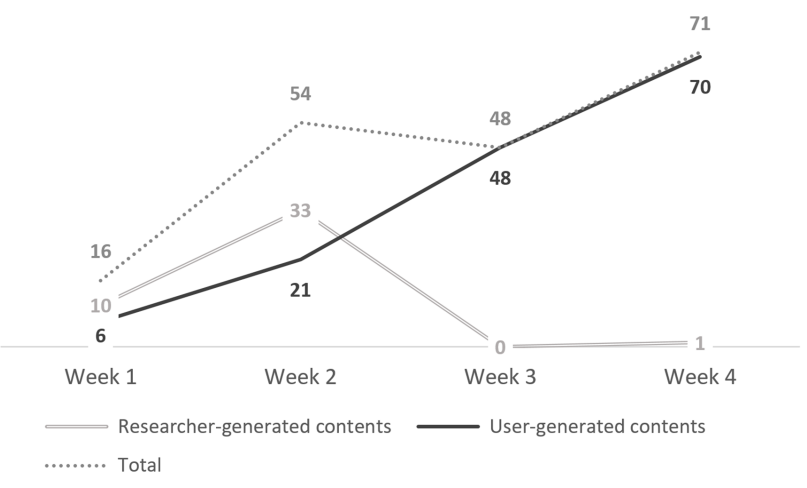

Figure 7. Distribution of Idea posts by users and researchers. Usergenerated content increased steadily over time.

Typically, photos and videos were taken shortly after each participant had finished her or his work. Only 14 photos (7.4\%) were recorded while participants were still in the process of making. In terms of visual styles, all photos and videos focused on the artifacts. Many artifacts were set against a solid background to make them stand out (see Figure 8). In compliance with the GDPR, identifiable faces did not appear in the images; only small parts of the body holding, or being near, the artifacts (e.g., hands or hair). Most photos and videos were posted without any description, and in the few instances that included text ( 24 out of 189 posts total; $12.7 \%$ ), the texts were brief (12-93 characters; Mdn=32). The texts gave short titles to the artifacts (e.g., "Sea monster with four eyes"), highlighted key features (e.g., "A nice aquarium to store rocks from the beach"), and provided some information about the source materials (e.g., "Homemade tambourine with bottle caps").

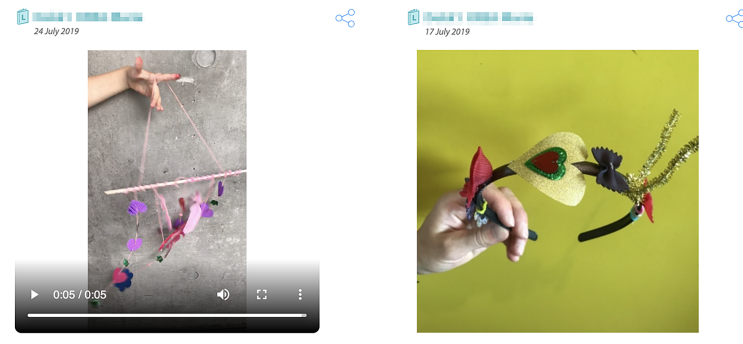

Figure 8. Examples of photos and videos of participants showcasing their crafts against the walls.
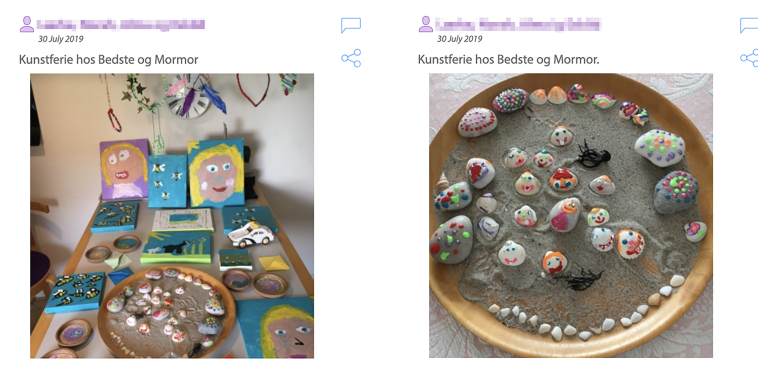

Figure 9. On week 4, two photos were shared by a family participating remotely from home.

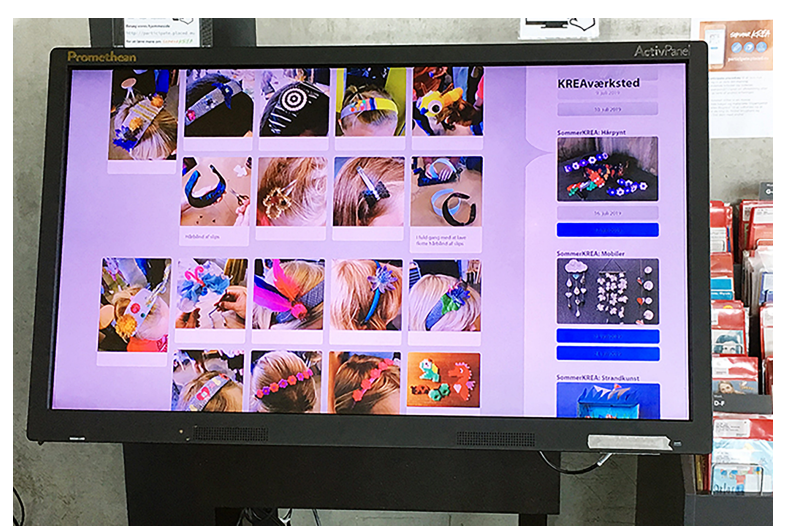

Figure 10. Idea posts shared on the public display.

Most of the posts $(75.7 \%)$ were generated by the event organizer, although some posts were generated by the researchers on behalf of users in response to explicit requests (23.3\%), particularly during the first two weeks of the system's deployment (see Figure 7 for the evolution of Idea posts). Finally, during week 4 , event participants generated two posts. Interestingly, these posts were submitted remotely, rather than onsite, yet in real time during the workshop session, implying that they were using PLACED to access a live feed of the event (see Figure 9). The event organizer shared all the Idea posts on the public display via the visualization module without exception. Collectively, the Idea posts yielded an extensive gallery of colorful photos and videos (see Figure 10).

\section{Books}

During week 1, users did not add any books to the Community Bookshelf feature. However, in the following three weeks, a total of 52 books were added to the community bookshelf by the event organizer. Specifically, during week 2, 20 books were added to its bookshelf, as were 9 written reviews. The reviews concisely highlighted the book's direct relevance to the workshop theme (40-145 characters; $\mathrm{Mdn}=89$ )(e.g., "Nice ideas for making brooches with many different materials. Most things can also be attached to a hair clip, headband or hair ties."). During week 3 and week 4, 21 and 11 books, respectively, were added to the community bookshelf, albeit without any reviews. The event organizer did not share any books on the public display. Instead, the event organizer built a physical bookshelf in the workshop area as shown in Figure 11. 

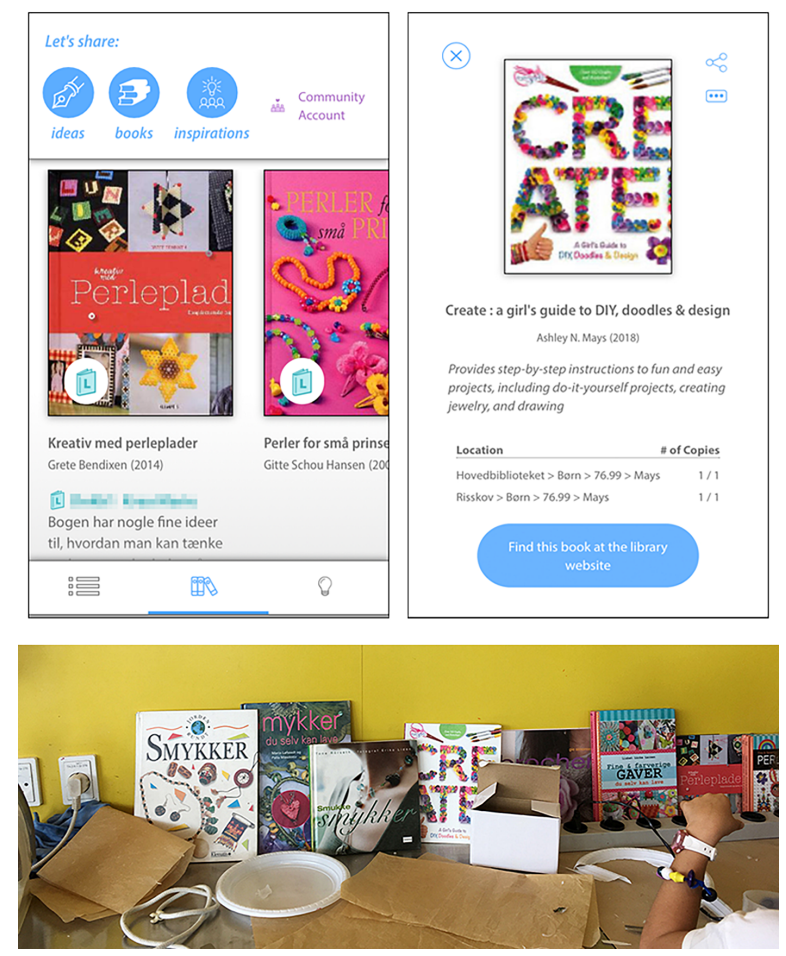

Figure 11. A digital bookshelf on the system (above) vs. a physical bookshelf in the workshop area (below).

\section{Inspirations}

The Inspirations feature was the least used of the three primary features. It had at least two limitations. First, the Inspirations feature was intentionally made ambiguous and open-ended, leaving it up to users to define its purpose. Second, for technical reasons it was not possible to share Inspiration posts on the public display. Despite these limitations, the event organizer generated two Inspiration posts. Interestingly, the texts accompanying the Inspiration posts were significantly longer than those accompanying the Idea posts or the Book posts (279-416 characters). The tone of the writing was personal and reflective, providing a meta-commentary on the Creative Workshop series as a whole, rather than on a particular theme of the week. See below for an example:

People's amazing ideas and the joy of being creative - It is so great to learn from each other's mistakes and successes and build on each other's ideas. When people leave the workshop with the feeling that they have created something from an idea to a product, and had a good and pleasant experience along the way, it makes me really happy. That is what makes me love my work more and more each time I run a workshop.

In this section, we described PLACED's utility in capturing and sharing emerging knowledge during an ongoing event at a public library. To briefly summarize, creative ideas were documented as photos and videos, extensive galleries and bibliographies were built at a community level, and personal reflections emerged.

\section{COMPUTATIONAL ALTERNATIVES VIGNETTES}

Here we present a collection of three computational alternatives vignettes. Computational alternatives vignette is a snapshot of the interplay among stakeholders, technology, and environment. Each computational alternative vignette contains an observation illustrating specific patterns of interaction that emerged around the prototype, accompanied by a reflection highlighting key insights gained from a local deployment and observations.

Like design fictions [4, 36], computational alternatives vignettes enables designers to think through the specific details and ramifications of a technology before it is fully adopted into a given domain. Yet, computational alternatives vignettes differ from design fictions in that they are grounded in robust observations of systems in use. They can be understood as a form of critical incident stories [16], highlighting remarkable incidents or patterns that can potentially have a significant effect in the domain in question. Taken together, computational alternatives vignettes aim to strike a balance between envisioning and realism, and to support reflection on viable design directions to follow.

The three vignettes were developed and curated by the lead author based on the field observation, particularly, to highlight significant changes in practices and behaviors that were likely influenced by the introduction of PLACED. More indepth report of the ethnographic findings is beyond the scope of this paper and will be reported elsewhere. To improve validity, the vignettes were reviewed and critiqued by another researcher who conducted the field observations.

\section{Vignette 1: The Making of a Third Place}

\section{Observation}

The visualization module was set up outside the workshop area (see Figures 4 and 6). This is a seating area where library users may play and watch children's animation films. This area is very close to the workshop space, but not directly connected to it. They used to be separate spaces with distinct functions. However, the visualization module established a relationship between these two spaces. During the event, the seating area was transformed into a reception area, where event participants spent time before and after the Creative Workshop, to chat and socialize. Thus, it created a new "third place" [26] in the library (see Figure 12).

Before the deployment, the experience of the event effectively began as participants entered the workshop room and ended when they walked out of the room. Now, with the visualization module, the experience begins before entering the workshop room, as people spend time learning about this week's theme, seeing other participants' work, becoming inspired, and mentally sketching what they want to create. After the workshop, participants take time to explore what others have made, and reflect on their work from a different perspective. As the event organizer stated, "During the activity, people are often so focused on their work, they often don't pay attention to what other people are making. It is good that they can also see what others have made, to get ideas for how things can be done differently." 


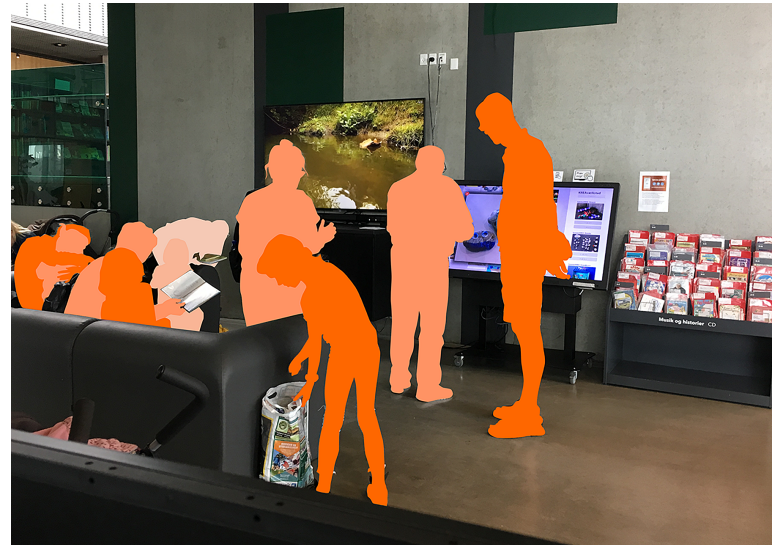

Figure 12. Seating area transformed into a third place. Event participants are interacting with the visualization module, reading books, and having conversations. No one is passively viewing the animation film. (Note: The image was taken during week 4 . We have outlined real people in order to protect their privacy)

\section{Reflection}

How did the visualization module fit [25] into the existing environment and then turned it into something else? What specific qualities made it possible for the visualization module to successfully own the space? Saliency of the physical presence, interactivity, and locality of the content were all critical to transforming the seating area into a third place.

Through its salient physical presence, the visualization module was able to claim immediately a certain amount of ownership of the place. Yet, we believe that its mere presence was not enough for it to take over the space. The visualization module was set up side by side with a bigger public film screen constantly streaming colorful animations. Sizewise, it could not compete. However, the visualization module had interactivity that the other public display did not have. UI hints and the tilted screen of the visualization module invited people to come closer and touch it, making people get up from their seats on the couch. Most importantly, the visualization module showcased a local, "native" content that was created and growing in the public library. In contrast, the public film screen played "foreign" materials produced from outside the library. In this respect, the visualization module, we believe, was able to establish a stronger tie to the place even if it was a newcomer.

As a whole, the visualization module was able to not only fit into the place but was able to own it. We suggest that place-centered technologies can develop stronger ownership of the space by supporting the qualities of saliency, interactivity, and locality. Yet, the work does not end here. To scaffold a third place, the system needs to foster social links that tie people together as a community. Public spaces by definition are occupied by multiple people. Yet, without the social links, people are merely collocated, rather than being together. We suggest community bookshelf and community gallery as actionable design opportunities for supporting the social links in public libraries. We discuss each in detail in Vignette 2 and Vignette 3.

\section{Vignette 2: Community Bookshelf}

\section{Observation}

The Bookshelf feature was one of the aspects that the event organizer valued the most. The feature motivated her to introduce more books to the event. It added extra work to her usual practice, yet she found it easy enough to generate a bibliography through PLACED. It was "something I can do over my morning coffee," the event organizer said.

Furthermore, the Bookshelf feature inspired the event organizer to fetch the books from the library shelves and physically display them so that participants could actually read and use them during the event, acquire new skills, and be inspired to create new things. Interestingly, the event organizer experimented with various options to find the best spot to display the books. First, the event organizer lined up the books on the glue-gun table (see Figure 11). The books were nicely arranged against the yellow wall, but it was difficult for participants to reach them over the glue-guns and electrical cords. The event organizer then moved the books to the workshop table, so that participants could more easily grab them as they made things. Finally, on week 4, the workshop was especially crowded, so the event organizer had to put people on a waiting list. The event organizer then had the idea of putting the books in the seating area, so that participants could read them while they waited (see Figure 12). The books became a conversation starter among participants as they picked up a book and and discussed different options for what they could make.

The Bookshelf feature not only allowed users to create a bibliography for the event, but it motivated the event organizer to take practical actions to integrate the books into the event in a way that improved her work practice, as well as the event participants' experience.

\section{Reflection}

Serholt et al.'s study [31] indicates that there is a strong desire from public libraries to establish a stronger link between the events and the library collection, in particular, by making use of books they have at the library. Yet it is not easy to do so. For instance, in the major public library we worked with, where more than 2000 events take place annually, library staff simply do not have time and resources to generate a bibliography for each single event. Furthermore, many of these events are hosted by external organizers who are not trained librarians, and for whom it is more challenging to identify relevant resources.

Our observation points toward opportunities for technologies to help create the link between the event and the library collection. The system we built allowed non-librarian users (e.g., the event organizer and the researchers) to build extensive bibliographies for the events. We also suggest that adding a ludic character can motivate users to engage more. For example, the automated book suggestion feature on PLACED, which one library staff characterized as the "Book Tinder" lowered the barriers for participation by making it feel less like work and more like fun. 


\section{Vignette 3: Community Gallery Observation}

Over time, we observed how documentation became routine for the event participants. As the event organizer said, "Kids quickly picked up on the idea that they can come to me for pictures and they will be added to the public display." Instead of just taking their artifacts and leaving, participants actively approached the event organizer to document their work, expecting it to become part of the library's digital collection. In particular, the event organizer played a critical role in setting an aesthetic standard for how to document photos and videos that are of high quality and comply with the GDPR ${ }^{2}$ (see Figure 9).

By single-handedly documenting all the photos and videos, the event organizer was able to maintain a cohesive look and feel for the digital collection. At the same time, each image was unique. The event organizer and participants often moved around to find the best photo spot, in particular, they searched for an interesting background to make each artifact stand out more. As a result, artifacts were set against yellow doors, cement walls, a black cabinet, deep green curtains, etc.

Interestingly, the visualization module (i.e., public display) itself became a popular photo spot. After documenting their work, event participants walked over to the visualization module to check their photos. Here, an unexpected experience emerged from a technical limitation that caused a slight time delay between the input from a mobile device and the projection on the public display. Furthermore, the position of a new photo was randomly assigned on the public display. Such unpredictability generated a pleasant thrill of anticipation among the users who were anxiously waiting in front of the public display, searching for their photos to appear somewhere on the screen. When the photo eventually popped up, there were joy and laughter. Participants often took a photo of their photo on the public display, sometimes with children posing proudly in front of the screen. It was not the photo itself that was important to the users, but they took pride in seeing their work as part of the library's digital collection.

\section{Reflection}

The ISO 16439 on methods and procedures for assessing the impact of libraries [14] identifies "the feeling of equality for all visitors, the sense of belonging" as a key aspect for assessing the library impact. For event participants, seeing their work in to the community gallery cultivated a sense of belonging. It is important to note the key difference between how the event organizer used Instagram and PLACED. On Instagram, the event organizer tends to share a few good exemplars from the workshop. In contrast, on PLACED the event organizer shared all the photos and videos without exception. Visually, the mosaic view and the random assignment of the image positions automated by the visualization module, as well as the coherent aesthetic style established by the event organizer, all contributed to fostering a feeling of equality. While one can never design others' feelings, our observation provides insights into how certain feelings can be supported through specific design attributes.

\footnotetext{
${ }^{2}$ European General Data Protection Regulation
}

Content moderation is a necessary feature in any community that builds on user-generated content, and librarians are particularly concerned with issues of curation [31]. However, given that all the content meet a certain quality level, our observation shows that indiscriminate display rather than curated display can lead to a greater sense of equality and belonging.

\section{DISCUSSION}

Placed-centered Design and Computational Alternatives As access to information becomes ubiquitous and computers are embedded in our environment, design becomes increasingly about the places and the activities people conduct [11, 19]. Designing for place encourages designers to ground their work in the "social, cultural and material conditions [and] account for the dynamics of place that continually change these conditions" [24]. The design of technological artifacts should focus on the stakeholders' local, situated practices, since meaning is created in the context and situation, often by the collaboration among the people, the artifact, the environment, and the resources available where the technology is used [20].

In our case, the overarching project goal was to support the emergence of third places in public libraries. With such sociotechnical ambition, we sketched strategies to effectively document local knowledge produced in library events and integrate such knowledge with the traditional library collection. Yet in spite of our long experience in designing for and with public knowledge institutions, it was difficult to envision exactly how this would play out in practice. What exact type of local knowledge will it capture/produce? How will such knowledge be used by whom for what purposes in which situations? How will new digital collections of events complement the traditional library collections, and vice versa? In what ways will technology fit into and alter existing places to create new third places? There is no easy answer to these questions; each of these questions are highly interrelated; they need to be investigated holistically and empirically through technology deployment. Computational Alternatives offer highly situated insights into these complex sociotechnical processes.

\section{Design for the very particular}

With PLACED, we strived to design for a very particular context of a local public library. We took this approach in reaction to a preliminary attempt in which we aimed at documenting all possible events. This attempt was too generic, and it was difficult to draw lessons from its trials. This led us to focus on a specific activity in a specific place discussed in the article. We argue that the vignettes we derived have generative power, not by generalizing to other places or activities, but rather by inspiring, challenging, or questioning stakeholders in other contexts.

This echoes Bertelsen et al. [3], who argue that the craving for generalization does not always increase validity or impact, but instead may at times abstract reality into a form where results can no longer be fed back into actual design questions in the real world. Inspired by Pape and Thoresen [27], they 
further suggest a cumulation of particulars in which each particular stands on its own. One benefit of such an approach is that it allows researchers to do impactful work, making a difference in a specific local community. Focusing on the very particular, we can learn how people, technology, and their environment influenced each other in one situation-in this case in one particular library event in one particular librarybefore we move on to the next event, and the next library.

\section{CONCLUSION AND FUTURE WORK}

In this paper, we set out to explore ways to enable organizers and participants of events in public libraries to capture aspects of the events and make these outcomes visible for the benefit of participants, library staff, and the wider community. In considering the analogy that knowledge produced in library events is similar, yet complementary, to the knowledge provided through the library's collection, we identified a need based on previous research [31] to raise the status of events to match the status of books and other library resources. Through a computational alternatives approach, we have designed and developed PLACED, a digital service that aims to capitalize on the knowledge produced in library events. Further, we have shown through a field study at a major public library, how this digital service came to be used in-situ. Moreover, we have utilized computational alternatives vignettes to exemplify and illustrate not only our observations during the field study, but also what this leads us to consider in terms of future design.

The Creative Workshop series is continuing to use PLACED. In addition, in parallel to the field study reported in this paper, we are designing two versions of PLACED for use in two partnering library sites. Like the design process detailed here, this entails a close working relationship with the library staff. In our future work, we will conduct similar field studies at these other libraries. Here, we have already witnessed certain variations in desired uses. For instance, in one of the sites, the librarians are the main producers of the showcased content (i.e., their own written reviews of the event). In the other library, the librarians have requested closed PLACED-groups for recurring events so that it can be used as a communication service for the regular participants. Given the malleable software stack that the PLACED is built upon, customized versions adapted for specific settings, and that answer to a variety of needs, can be quickly developed and implemented.

The contribution of this paper comprises a set of methodological reflections relevant for the HCI community, but arguably the most significant contribution of our project in a wider context lies realizing and demonstrating that digital services such as PLACED hold the potential to make visible and support the community-building potentials of public libraries.

\section{ACKNOWLEDGMENTS}

Thanks to all who took part in this study. We are grateful for the technical support provided by CAVI, especially Janus Bager Kristensen and Rolf Bagge. The work is funded by Vinnova 2017-01553, Innovation Fund Denmark 512300007B, Agence Nationale de la Recherche ANR-16-ENSF0004, and JPI Urban Europe EU 693443.

\section{REFERENCES}

[1] Noorhidawati Abdullah, Samuel Chu, Sandhya Rajagopal, Abigail Tung, and Yeung Kwong-Man. 2015. Exploring Libraries' Efforts in Inclusion and Outreach Activities Using Social Media. International Journal of Libraries and Information Studies 65, 1 (2015), 34-47. DOI:

http://dx.doi .org/10.1515/libri-2014-0055

[2] Maija Berndtson. 2013. Public libraries and placemaking. In IFLA WLIC 2013 - Singapore - Future Libraries: Infinite Possibilities. IFLA, Singapore, 1-10. http://library.ifla.org/id/eprint/224

[3] Olav W. Bertelsen, Susanne Bødker, Eva Eriksson, Eve Hoggan, and Jo Vermeulen. 2018. Beyond Generalization: Research for the Very Particular. Interactions 26, 1 (Dec. 2018), 34-38. DOI : http://dx.doi . org/10.1145/3289425

[4] Julian Bleecker. 2009. Design Fiction: A short essay on design, science, fact and fiction. Near Future Laboratory 29 (2009).

[5] Susanne Bødker and Ole Sejer Iversen. 2002. Staging a Professional Participatory Design Practice: Moving PD Beyond the Initial Fascination of User Involvement. In Proceedings of the Second Nordic Conference on Human-computer Interaction (NordiCHI '02). ACM, New York, NY, USA, 11-18. DOI : http://dx.doi.org/10.1145/572020.572023

[6] Bertram C Bruce, Andee Rubin, and Junghyun An. 2010. Situated evaluation of socio-technical systems. In Social Computing: Concepts, Methodologies, Tools, and Applications. IGI Global, 2211-2225.

[7] Parmit K. Chilana, Andrew J. Ko, and Jacob Wobbrock. 2015. From User-Centered to Adoption-Centered Design: A Case Study of an HCI Research Innovation Becoming a Product. In Proceedings of the 33rd Annual ACM Conference on Human Factors in Computing Systems (CHI'15). ACM, New York, NY, USA, 1749-1758. DOI : http://dx.doi.org/10.1145/2702123.2702412

[8] Terry Costantino, Steven LeMay, Linnea Vizard, Heather Moore, Dara Renton, Sandra Gornall, and Ian Strang. 2014. Exploring Participation in the Design of Public Library e-Services. In Proceedings of the 13th Participatory Design Conference: Short Papers, Industry Cases, Workshop Descriptions, Doctoral Consortium Papers, and Keynote Abstracts - Volume 2 (PDC '14). ACM, New York, NY, USA, 17-20. DOI : http://dx.doi.org/10.1145/2662155.2662174

[9] Peter Dalsgaard, Christian Dindler, and Eva Eriksson. 2008. Designing for Participation in Public Knowledge Institutions. In Proceedings of the 2008 Nordic Conference on Human-computer Interaction: Building Bridges (NordiCHI '08). ACM, New York, NY, USA, 93-102. DOI :

http://dx.doi.org/10.1145/1463160.1463171 
[10] Peter Dalsgaard and Eva Eriksson. 2013. Large-scale Participation: A Case Study of a Participatory Approach to Developing a New Public Library. In Proceedings of the SIGCHI Conference on Human Factors in Computing Systems (CHI '13). ACM, New York, NY, USA, 399-408. DOI :

http://dx.doi.org/10.1145/2470654.2470713

[11] Paul Dourish. 2004. What We Talk About when We Talk About Context. Personal Ubiquitous Comput. 8, 1 (Feb. 2004), 19-30. DOI :

http://dx . doi .org/10.1007/s00779-003-0253-8

[12] Anthony Dunne and Fiona Raby. 2013. Speculative everything: design, fiction, and social dreaming. MIT press.

[13] Yrjö Engeström. 2015. Learning by expanding. Cambridge University Press.

[14] International Organization for Standardization. 2014. International Standard ISO 16439: Information and Documentation: Methods and Procedures for Assessing the Impact of Libraries. ISO.

[15] Bill Gaver, Tony Dunne, and Elena Pacenti. 1999. Design: cultural probes. interactions 6, 1 (1999), 21-29. DOI: http://dx.doi .org/10.1145/291224.291235

[16] Dwayne D Gremler. 2004. The critical incident technique in service research. Journal of service research 7, 1 (2004), 65-89.

[17] Carla Gröschel, Peter Dalsgaard, Clemens N. Klokmose, Henrik Korsgaard, Eva Eriksson, Raphaëlle Bats, Aurélien Tabard, Alix Ducros, and Sofia E. Serholt. 2018. PARTICIPATE: Capturing Knowledge in Public Library Activities. In Extended Abstracts of the 2018 CHI Conference on Human Factors in Computing Systems (CHI EA '18). ACM, New York, NY, USA, Article LBW060, 6 pages. DOI: http://dx.doi.org/10.1145/3170427.3188605

[18] Bruce Hanington and Bella Martin. 2012. Universal methods of design: 100 ways to research complex problems, develop innovative ideas, and design effective solutions. Rockport Publishers.

[19] Steve Harrison and Paul Dourish. 1996. Re-place-ing Space: The Roles of Place and Space in Collaborative Systems. In Proceedings of the 1996 ACM Conference on Computer Supported Cooperative Work (CSCW '96). ACM, New York, NY, USA, 67-76. DOI : http://dx.doi.org/10.1145/240080.240193

[20] Jina Huh, Mark S. Ackerman, Thomas Erickson, Steve Harrison, and Phoebe Sengers. 2007. Beyond Usability: Taking Social, Situational, Cultural, and Other Contextual Factors into Account. In CHI '07 Extended Abstracts on Human Factors in Computing Systems (CHI EA '07). ACM, New York, NY, USA, 2113-2116. DOI:http://dx.doi.org/10.1145/1240866.1240961

[21] Hilary Hutchinson, Wendy Mackay, Bo Westerlund, Benjamin B. Bederson, Allison Druin, Catherine
Plaisant, Michel Beaudouin-Lafon, Stéphane Conversy, Helen Evans, Heiko Hansen, Nicolas Roussel, and Björn Eiderbäck. 2003. Technology Probes: Inspiring Design for and with Families. In Proc. ACM CHI 'O3. ACM, New York, NY, USA, 17-24. DOI : http://dx.doi.org/10.1145/642611.642616

[22] Clemens N. Klokmose, James Eagan, Siemen Baader, Wendy Mackay, and Michel Beaudouin-Lafon. 2016. Webstrates: Demonstrating the Potential of Shareable Dynamic Media. In Proceedings of the 19th ACM Conference on Computer Supported Cooperative Work and Social Computing Companion (CSCW'16 Companion). ACM, New York, NY, USA, 61-64. DOI : http://dx.doi .org/10.1145/2818052.2874325

[23] Henrik Korsgaard, Clemens Nylandsted Klokmose, and Susanne Bødker. 2016. Computational Alternatives in Participatory Design: Putting the T Back in Socio-technical Research. In Proceedings of the 14th Participatory Design Conference: Full Papers - Volume 1 (PDC '16). ACM, New York, NY, USA, 71-79. DOI: http://dx.doi .org/10.1145/2940299.2940314

[24] Jörn Messeter. 2009. Place-specific computing: A place-centric perspective for digital designs. International Journal of Design 3, 1 (2009), 29-41.

[25] William Odom, Ron Wakkary, Youn-kyung Lim, Audrey Desjardins, Bart Hengeveld, and Richard Banks. 2016. From research prototype to research product. In Proceedings of the $2016 \mathrm{CHI}$ Conference on Human Factors in Computing Systems. ACM, 2549-2561. DOI :

http://dx.doi.org/10.1145/2858036.2858447

[26] R Oldenburg. 1989. The Great Good Place: Cafes, Coffee Shops, Bookstores, Bars, Hairsalons and Other Hangouts at the Heart of Community. Marlowe and Company.

[27] T.C. Pape and K. Thoresen. 1987. Development of common systems by prototyping. In Computers and Democracy: A Scandinavian Challenge, Gro Bjerknes, Pelle Ehn, and Morten Kyng (Eds.). Gower Pub Co.

[28] Beth Posner. 2002. Urban Librarianship: Libraries, Cities and Beyond. In CUNY Academic Works. CUNY, New York, NY, USA, 1-24. http://academicworks. cuny. edu/gc_pubs/342

[29] Vicky Reich and Mark Weiser. 1994. Libraries are more than information: Situational aspects of electronic libraries. Serials Review 20, 3 (1994), 31-37. DOI : http://dx.doi.org/10.1016/0098-7913(94)90037-X

[30] Antti Salovaara, Antti Oulasvirta, and Giulio Jacucci. 2017. Evaluation of Prototypes and the Problem of Possible Futures. In Proceedings of the 2017 CHI Conference on Human Factors in Computing Systems. ACM, 2064-2077. DOI :

http://dx.doi.org/10.1145/3025453.3025658 
[31] Sofia Serholt, Eva Eriksson, Peter Dalsgaard, Raphälle Bats, and Alix Ducros. 2018. Opportunities and Challenges for Technology Development and Adoption in Public Libraries. In Proceedings of the 10th Nordic Conference on Human-Computer Interaction (NordiCHI '18). ACM, New York, NY, USA, 311-322. DOI: http://dx.doi .org/10.1145/3240167.3240198

[32] Jesper Simonsen and Toni Robertson. 2012. Routledge international handbook of participatory design. Routledge.

[33] Emma Simpson, Rob Comber, Andrew Garbett, Ed Ian Jenkins, and Madeline Balaam. 2017. Experiences of Delivering a Public Health Data Service. In Proceedings of the 2017 CHI Conference on Human Factors in Computing Systems (CHI '17). ACM, New York, NY, USA, 6171-6183. DOI : http://dx.doi.org/10.1145/3025453.3025881

[34] Aurélien Tabard, Juan David Hincapié Ramos, and Jakob Bardram. 2012. The eLabBench in the Wild: Supporting Exploration in a Molecular Biology Lab. In Proceedings of the SIGCHI Conference on Human Factors in Computing Systems (CHI '12). ACM, New York, NY, USA, 3051-3060. DOI:

http://dx.doi.org/10.1145/2207676.2208718

[35] Aurélien Tabard, Wendy E. Mackay, and Evelyn Eastmond. 2008. From Individual to Collaborative: The Evolution of Prism, a Hybrid Laboratory Notebook. In Proceedings of the 2008 ACM Conference on
Computer Supported Cooperative Work (CSCW '08). ACM, New York, NY, USA, 569-578. DOI : http://dx. doi .org/10.1145/1460563.1460653

[36] Joshua Tanenbaum. 2014. Design fictional interactions: why HCI should care about stories. interactions 21,5 (2014), 22-23. DOI : http://dx. doi .org/10.1145/2648414

[37] Kaya van Beynen and Camielle Swenson. 2016. Exploring Peer-to-Peer Library Content and Engagement on a Student-Run Facebook Group. College \& Research Libraries 77, 1 (2016), 34-50. DOI: http://dx.doi.org/10.5860/crl.77.1.34

[38] Jon Whittle. 2014. How much participation is enough?. In Proceedings of the 13th Participatory Design Conference on Research Papers - PDC '14. ACM Press. DOI : http://dx. doi .org/10.1145/2661435.2661445

[39] Jason Yip and Kung Jin Lee. 2018. The Design of Digital Learning Activities for Libraries Through Participatory Design. In Reconceptualizing Libraries. Routledge, 203-216. DOI :

http://dx.doi.org/10.4324/9781315143422-12

[40] Daisy Yoo, Anya Ernest, Sofia Serholt, Eva Eriksson, and Peter Dalsgaard. 2019. Service Design in HCI Research: The Extended Value Co-creation Model. In Proceedings of the Halfway to the Future Symposium 2019. ACM, 17. DOI :

http://dx.doi.org/10.1145/3363384.3363401 